\section{Cochrane and the new McCarthyism}

Published online on November 24, 2018.DOI:10.20529/ IJME.2018.094

Srivatsan's powerful commentary in this journal (1) is an important reminder that we live in an era of new McCarthyism'

The issue of the sacking of Peter Gøtzche from Cochrane is complex and has two linked aspects. The first is the fact of his dismissal and the second is our work on Human Papillomavirus (HPV) vaccines.

Peter Gøtzche's dismissal was because of "bad behaviour", defined by the Cochrane Board as "a repeated presentation of personal views as those of Cochrane despite requests and promises not do so" and "Serious defamatory and outrageous allegations against Cochrane colleagues - and publicly". The full list of "charges" can be accessed on the Cochrane website (2). So far, no hard evidence to back these "charges" has ever been produced by the minority Management Board. Peter Gøtzche was sacked because his style and his message are not popular in an organisation which has lost sight of its founding goals and is intent on tightly controlling the release of information it produces. Those present at the Annual General Meeting in September, or those who have watched the recording (3), will remember the sheer venom with which Peter's expulsion was discussed. It was all a lot of smoke and personality clashes and little substance. Balanced statements, proposals and analyses of the facts can be found in the statement by the Directors of the Iberoamerican Cochrane Network (4): and in the comment of David Hammerstein, one of the four Board members who resigned in protest at Gotzsche's expulsion. (5).

The Cochrane Collaboration was established in 1993 to help people reach more reliable conclusions about the benefits and harms of interventions than was otherwise possible at the time. Ours was a cultural movement based on openness, collaboration, and what the members thought, at the time, to be a good basis of fact: journal publications of clinical trials. As time went by, it became clear that these were, in most cases, no better than nice stories with exaggerated claims of benefits and forgotten or miniaturised harms reporting. This is why, after our experience with our Tamiflu Cochrane review (6), we decided to review the evidence based for HPV vaccines focussing only on regulatory data. Regulatory data are still part of a commercial operation: getting your intervention to market. However, they are far more detailed and reliable than 10-page journal summaries. We started by asking the European regulator, the European Medicines Agency, for clinical study reports. We have documented the difficulties encountered and the correspondence (7). Despite the difficulties, we succeeded in creating an index of 206 prospective comparative studies of HPV vaccines (8). This unique achievement is aimed at addressing publication bias and minimising the effects of other types of reporting bias, effectively providing an alternative to journal-published articles and their databases (9).

A copy of the index was sent to the Cochrane editors and the review group finalising the HPV review on the day of publication: January 19, 2018. They took no notice of the index, its content and implications, and published a biased and factually wrong review (10). We responded publicly pointing out the list of problems (11). It now turns out that our list was rather conservative (12). The Cochrane editors responded with an urgent investigation which is nothing more than the rest: smoke to hide their dismissal of our Index and its implications. Shortly after, Peter Gøtzsche, the man who has done more than anyone else to open our eyes to the shortcomings of published trials was sacked.

Despite the mounting evidence for the need to switch to an alternative form of "E" for EBM (9) Cochrane has taken no corporate action, concentrating on commercial mantras like "brand", dropping our hallowed "Collaboration" from the name. The story is by no means finished as we will publish our review of the regulatory evidence, with the Editor-in-Chief of BMJ EBM leading further scrutiny of the Arbyn et al review.

But do HPV vaccines cause serious harms? To that I can only answer that the trials were not designed to test harms fairly with their combination of idiosyncratic harms categorisation, reporting and the use of active comparators dubbed "placebo".

Now the current Cochrane leadership wants to carry on as if the entire controversy was nothing serious.

Tom Jefferson (jefferson.tom@gmail.com), Senior Associate Tutor, University of Oxford, Oxford OX2 6GG, UK

\section{Disclosure}

TJ was a recipient of a UK National Institute for Health Research grant for a Cochrane review of neuraminidase inhibitors for influenza. In addition, TJ receives royalties from his books published by II Pensiero Scientifico Editore, Rome and Blackwell's. $T J$ is occasionally interviewed by market research companies about phase I or II pharmaceutical products. In 2011-13, TJ acted as an expert witness in litigation related to the antiviral oseltamivir, in two litigation cases on potential vaccine-related damage (including the vaccine Pandemrix (2015-2017) and in a labour case on influenza vaccines in healthcare workers in Canada. He has acted as a consultant for Roche (1997-99), GSK (2001-2), Sanofi-Synthelabo (2003), and IMS Health (2013). In 2014 he was retained as a scientific adviser to a legal team acting on oseltamivir. TJ has a potential financial conflict of interest in the drug oseltamivir. In 2014-16, TJ was a member of 
three advisory boards for Boehringer Ingelheim. TJ was holder of a Cochrane Methods Innovations Fund grant to develop guidance on the use of regulatory data in Cochrane reviews. $T J$ was a member of an independent data monitoring committee for a Sanofi Pasteur clinical trial on an influenza vaccine. Between 1994 and 2013, TJ was the coordinator of the Cochrane Vaccines Field. TJ was a co-signatory of the Nordic Cochrane Centre Complaint to the European Medicines Agency (EMA) over maladministration at the EMA in relation to the investigation of alleged harms of HPV vaccines (7), and consequent complaints to the European Ombudsman. TJ is co-holder of a John and Laura Arnold Foundation grant for development of a RIAT support centre (2017-2020) and Jean Monnet Network Grant, 20172020 for The Jean Monnet Health Law and Policy Network. TJ is an unpaid collaborator to the project Beyond Transparency in Pharmaceutical Research and Regulation led by Dalhousie University and funded by the Canadian Institutes of Health Research (2018-2022). The Laura and John Arnold Foundation funds the RIAT Support Center which supports the salaries of Dr. Doshi, Dr. Jones, and Dr. Jefferson.

'Note: "McCarthyism", after Wisconsin senator Joe McCarthy, became the label for the tactic of undermining political opponents by making unsubstantiated attacks on their loyalty to the United States.

\section{References}

1. Srivatsan R. Storm in a teacup? General implications of the Cochrane crisis. Indian J Med Ethics. Published online on October 20, 2018 [cited 2018 Oct 24]. DOI:10.20529/IJME.2018.079. Available from: http://ijme. in/articles/storm-in-a-teacup-general-implications-of-the-cochranecrisis/?galley $=\mathrm{html}$

2. Cochrane Community. Governing Board webinars - October 2018 [cited 2018 Oct 24]. Available from: https://community.cochrane.org/news/ governing-board-webinars-october-2018

3. Cochrane Annual General Meeting, Edinburgh, 2018 Sep 17[cited 2018 Oct 24]. Available from: https://www.youtube.com/watch?v=cLG5NKph Xq0\&feature=youtu.be
4. Cochrane Iberoamerica. The Cochrane Iberoamerican Network asks to improve the governance of the organisation as well as transparency, participation and an independent review of the Peter Gøtzsche's process. Nogracias.eu. 2018 Oct 6[cited 2018 Oct 24]. Available from: http://www.nogracias.eu/2018/10/06/the-cochrane-iberoamericannetwork-asks-to-improve-the-governance-of-the-organisation-as-wellas-transparency-participation-and-an-independent-review-of-thepeter-gotzsches-process/

5. Hammerstein D. Regenerate Cochrane to strengthen the production of trusted evidence for the common good of public health. Nogracias.eu. 2018 Oct 8[cited 2018 Oct 24]. Available from: http://www.nogracias. eu/2018/10/08/regenerate-cochrane-to-strengthen-the-productionof-trusted-evidence-for-the-common-good-of-public-health-by-davidhammerstein/

6. Jefferson $\mathrm{T}$, Jones $\mathrm{M}$, Doshi $\mathrm{P}$, Spencer EA, Onakpoya I, Henegan CJ. Oseltamivir for influenza in adults and children: systematic review of clinical study reports and summary of regulatory comments. BMJ. 2014 Apr 9;348:g2545. doi: 10.1136/bmj.g2545

7. Jørgensen L, Doshi P, Gøtzsche P, Jefferson T. Challenges of independent assessment of potential harms of HPV vaccines. BMJ. 2018 Sep 24;362: k3694 doi: 10.1136/bmj.k3694

8. Jorgensen L, Gotzsche PC, Jefferson T. Index of the human papillomavirus (HPV) vaccine industry clinical study programmes and non-industry funded studies: a necessary basis to address reporting bias in a systematic review. Syst Rev. 2018 Jan 18;7(1):8. doi: 10.1186/s13643-0180675-z.

9. Jefferson T, Jorgensen L. Redefining the 'E' in EBM. BMJ Evid Based Med. 2018 Apr; 23(2): 1-5.doi: 10.1136/bmjebm-2018-110918. Epub 2018 Mar 9.

10. Arbyn $M, X u$ L, Simoens $C$, Martin-Hirsch PPL. Prophylactic vaccination against human papillomaviruses to prevent cervical cancer and its precursors. Cochrane Database Syst Rev 2018 May 9;5:CD009069. doi: 10.1002/14651858.CD009069.pub3.

11. Jorgensen L, Gøtzsche PC, Jefferson T.The Cochrane HPV vaccine review was incomplete and ignored important evidence of bias. BMJ Evid Based Med. 2018 July 27 [cited 2018 Oct 24]. Available from: https://doi. org/10.1136/bmjebm-2018-111012.

12. Doshi $P$, Jones $M$, Jefferson $T$. Concerns about accuracy of mortality metaanalysis. Cochranelibrary.com. 2018 Oct 17[cited 2018 Oct 24]. Available from: https://www.cochranelibrary.com/cdsr/doi/10.1002/14651858. CD009069.pub3/detailed-comment/en?messageld=157077507.

\section{Be a part of IJME}

IJME invites readers to submit research studies, comments, case studies, reports, reviews, letters, as also poems, short stories, original paintings and photographs of print quality ( both in colour and $\mathrm{B} / \mathrm{W}$ ) to be considered for publication.

All submitted matter is subject to peer review.

Contributors are neither paid nor charged any fee for published matter. 